IMAGE

\title{
Insights Image for "Effect of prebiotic and probiotic supplementation on neurodevelopment in preterm very low birth weight infants: findings from a meta-analysis"
}

Ravi Prakash Upadhyay ${ }^{1}$, Sunita Taneja ${ }^{1}$, Ranadip Chowdhury ${ }^{1}$, Tor A. Strand ${ }^{2,3}$ and Nita Bhandari ${ }^{1}$

Pediatric Research (2020) 87:969; https://doi.org/10.1038/s41390-019-0616-0

Pathways through which prebiotic/probiotic supplementation in preterm very low birth weight infants could influence neurodevelopment.

\section{REFERENCES}

1. Upadhyay, R. et al. Effect of prebiotic and probiotic supplementation on neurodevelopment in preterm very low birth weight infants: findings from a meta-analysis. Pediatric Res. (2018). https://www.nature.com/articles/s41390018-0211-9

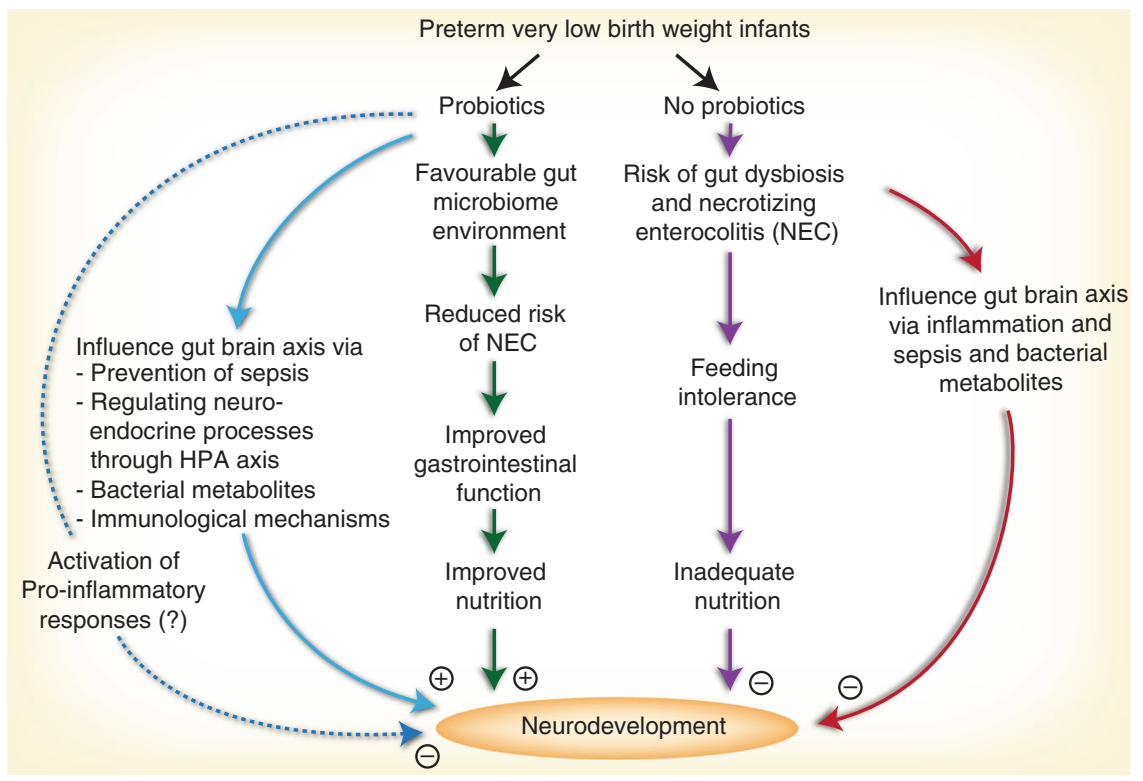

\footnotetext{
${ }^{1}$ Centre for Health Research and Development, Society for Applied Studies, New Delhi, India; ${ }^{2}$ Centre for Intervention Science in Maternal and Child Health, Centre for International Health, University of Bergen, Bergen, Norway and ${ }^{3}$ Department of Research, Innlandet Hospital Trust, Brumunddal, Norway Correspondence: Ravi Prakash Upadhyay (ravi.upadhyay@sas.org.in)
} 